
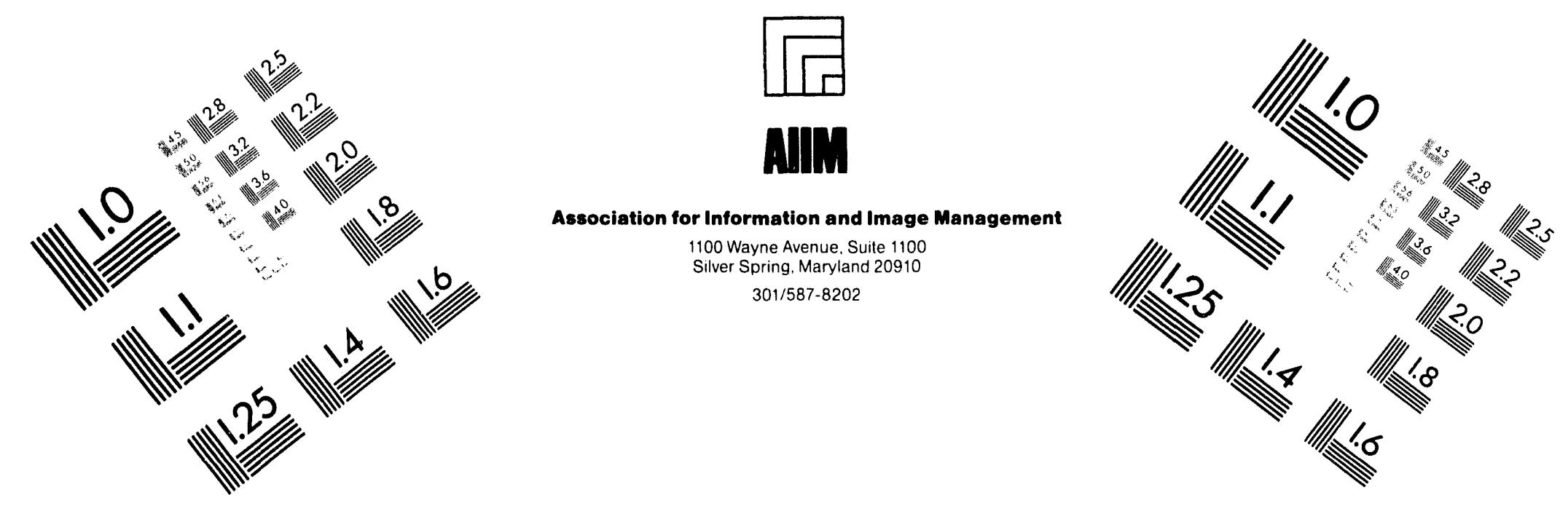

\title{
Centimeter
}

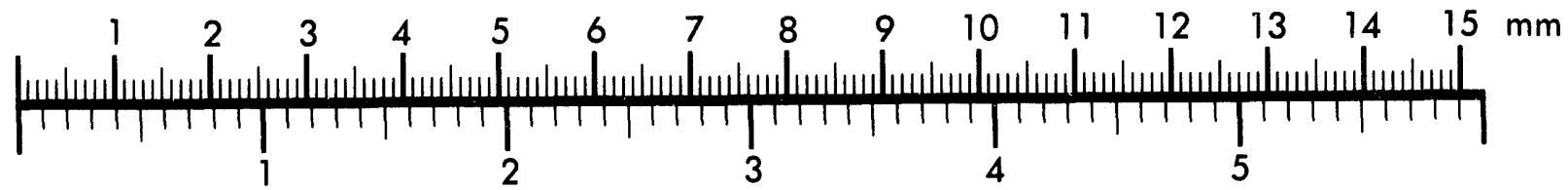
Inches
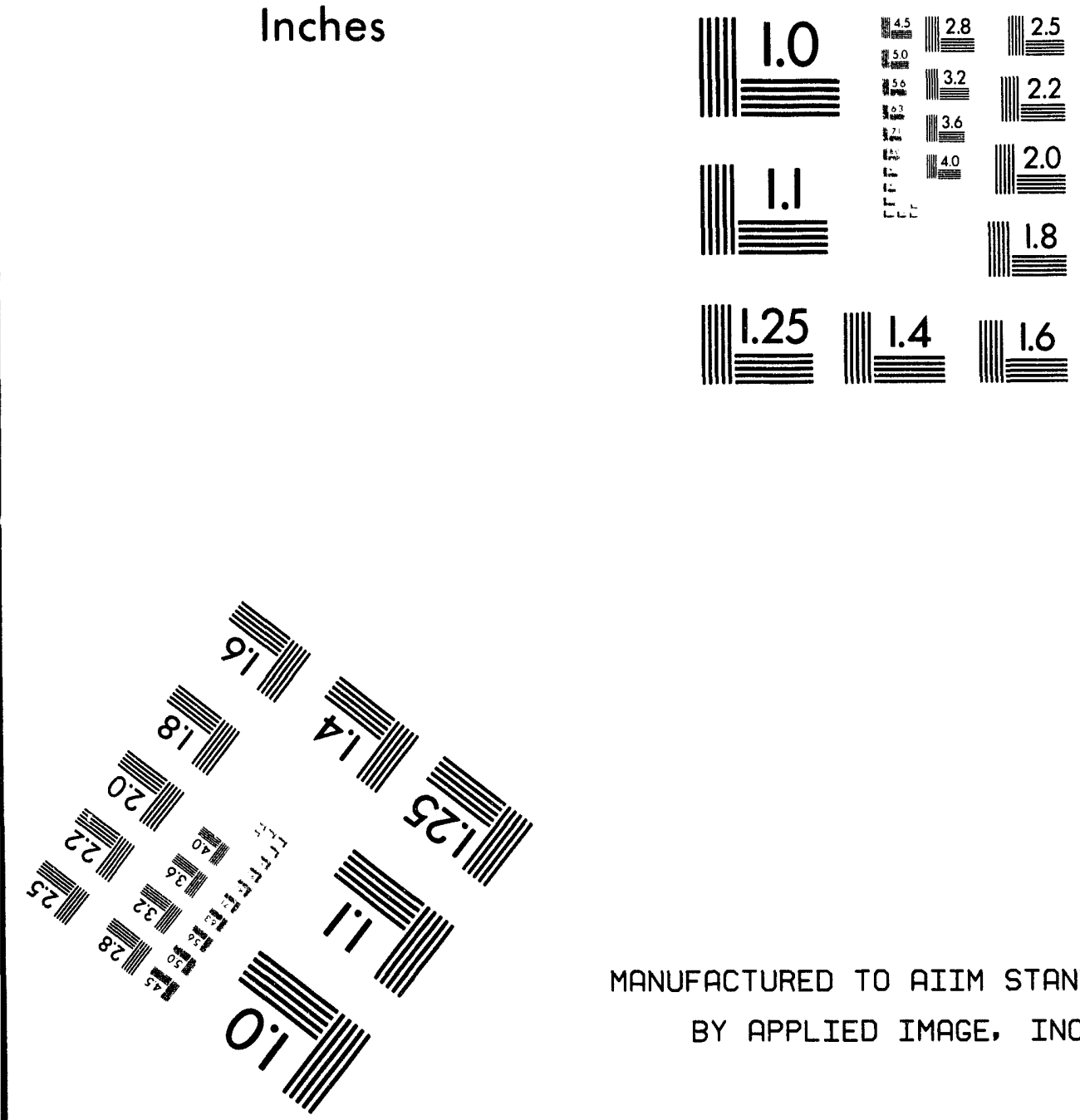

MANUFACTURED TO AIIM STANDARDS BY APPLIED IMAGE, INC.

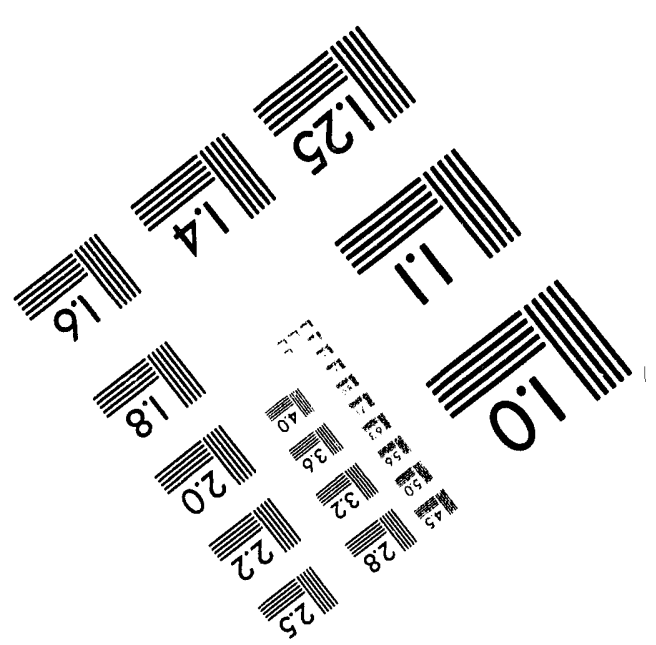



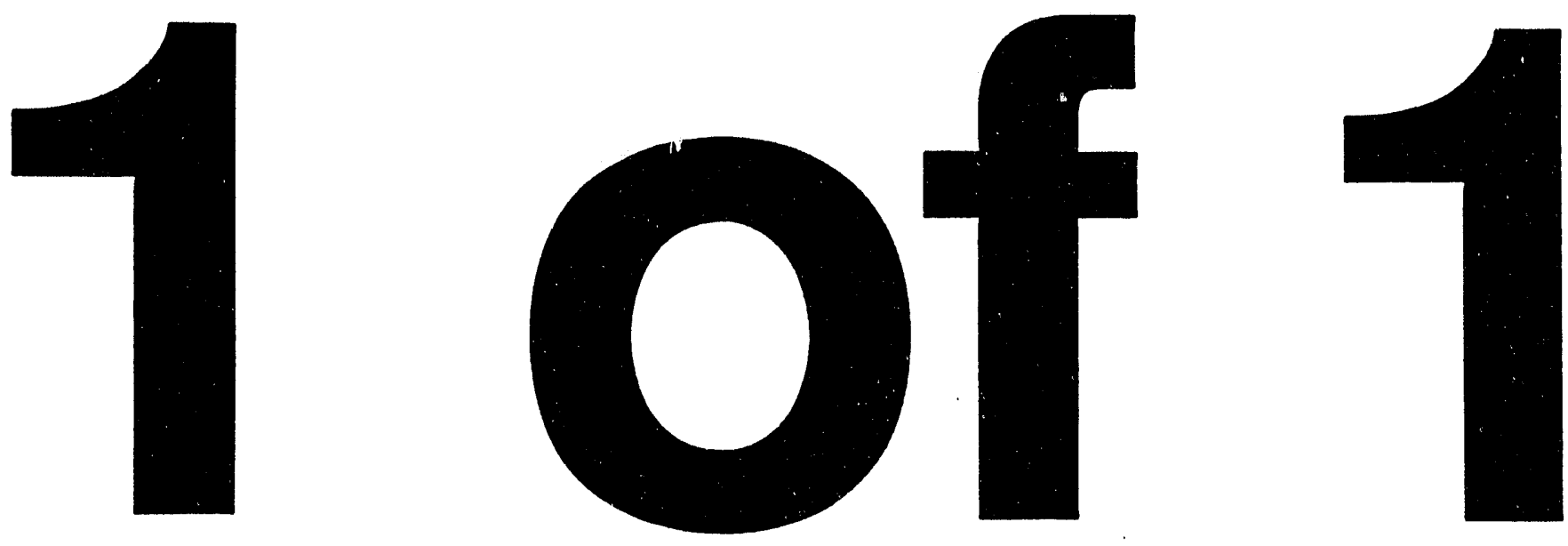


\title{
Corf- $9409102-1$
}

UCRL-JC-116176

PREPRINT

\section{Model-Based Ocean Acoustic Passive Localization}

\author{
J. V. Candy \\ E. J. Sullivan
}

RECEIVED

APR 13 1994

OSTI

This paper was prepared for submittal to the

Oceans 94 Conference

Brest, France

September 13-16, 1994

January 24, 1994

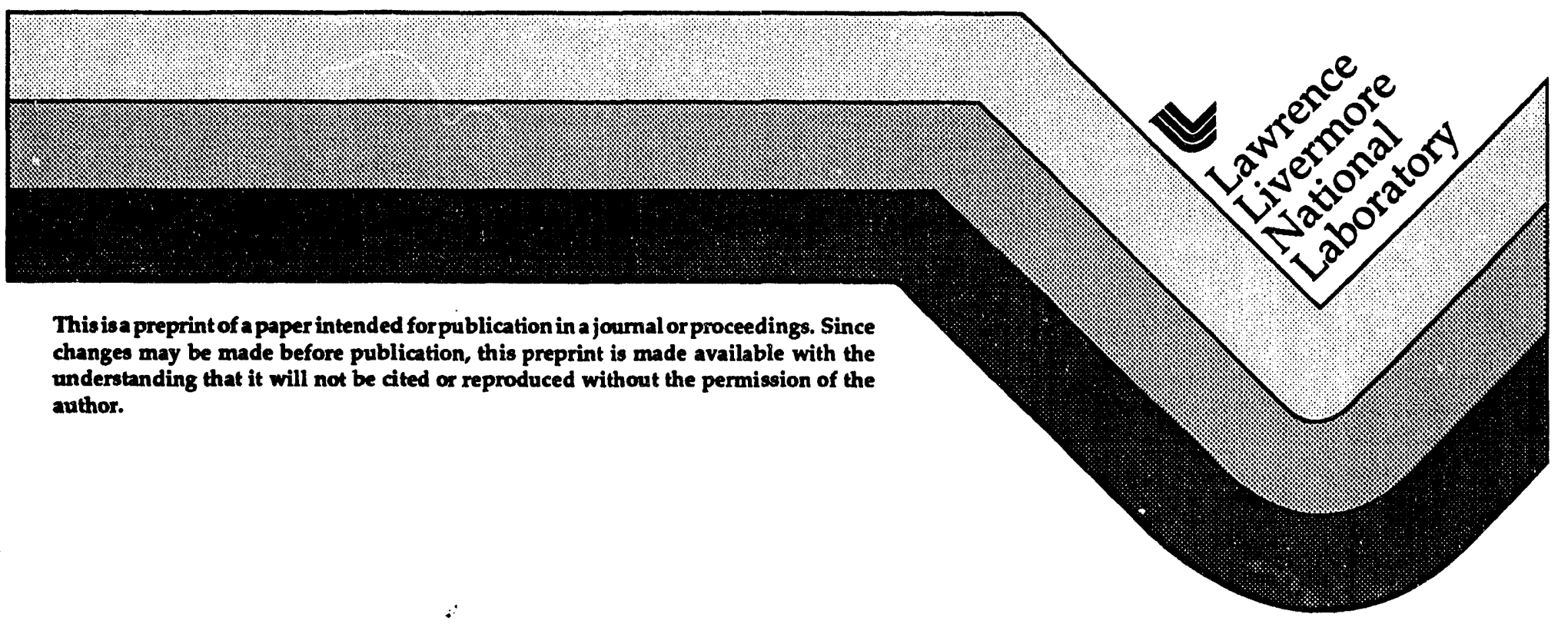

MASTER

$d a$

DSTIMBUUTION OF THIS DOCUNENT IS UNLIMITCA 
This document was prepared as an account of work sponsored by an agency of the United States Government. Neither the United States Government nor the University of California nor any of their employees, makes any warranty. express or implied, or assumes any legal liability or responsibility for the accuracy. completeness, or usefulness of any information, apparatus, product, or process disclosed, or represents that its use would not infringe privately owned rights. Reference herein to any specific commercial products, process, or service by trade mame. trademark, manufacturer, or otherwise, does not necessarily constitute or imply its endorsement, recommendation, or favoring by the United States Government or the University of California. The views and opinions of authors expressed herein do not necessarily state or reflect those of the United States Government or the University of California, and shall not be used for advertising or product endorsement purposes. 


\title{
MODEL-BASED OCEAN ACOUSTIC PASSIVE LOCALIZATION
}

\author{
J. V. Candy ${ }^{\dagger}$ \\ University of California \\ Lawrence Livermore National Laboratory \\ P.O. Box 5504, L-495 \\ Livermore, $C A 94551$ \\ E. J. Sullivan \\ Naval Undersea Warfare Center \\ NUWC Code 103 \\ Newport, RI.02841
}

\section{Summary}

The detection, localization and classification of acoustic sources (targets) in a hostile ocean environment is a difficult problem-especially in light of the improved design of modern submarines and the continual improvement in quieting technology. Further the advent of more and more diesel-powered vessels makes the detection problem even more formidable than ever before. It has recently been recognized that the incorporation of a mathematical model that accurately represents the phenomenology under investigation can vastly improve the performance of any processor, assuming, of course, that the model is accurate. Therefore, it is necessary to incorporate more knowledge about the ocean environment into detection and localization algorithms in order to enhance the overall signal-to-noise ratios and improve performance. Recently, there have been many improvements to the signal processing of acoustical sources in the literature -especially in the area of high resolution spatial processing (beamforming) for passive localization (e.g. Johnson, 1982; Van Veen, 1988). Beamforming incorporates information on the "assumed" wavefront, here the direction vector of an impinging plane wave source. As the ocean environment becomes more and more complicated, such as in our case, then the "plane wavefront" model fails, leading to severe beamformer performance degradation.

In an effort to improve the performance of the beamformer for complex ocean environments - the matched-field processor has evolved as a potential solution. Here the plane wavefront "steering" vector is replaced with the general wavefront "matching" vector generated by a sophisticated propagation model characterizing the operational ocean environment. The matched-field processor performance is highly dependent on the capabilty of the propagation model to replicate the actual ocean (e.g. Hinich,1973; Sullivan, 1987a,b; Hamson,1989; Feuillade, 1989; Candy,1990). When the replication is reasonable, performance is good; however, degradation can be severe when there is a significant mismatch, especially in the sound speed profile, which influences the particular sound propagation channel. In a recent paper (Sullivan and Middleton,1993), it was shown that the matched-field problem should be placed into the estimation framework in order to evaluate and analyze performance when employing a complicated propagation model. Thus, we must have some way

$\dagger$ This work received partial support from the Office of the Chief of Naval Research, OCNR N00014-91-F-0114 and the Lawrence Livermore National Laboratory under the auspices of the U.S. Department of Energy, DOE Contract W-7405-ENG-48. 
to determine with high confidence that the models employed are valid in a given volume of ocean.

An alternative methodology to matched-field/matched-mode processing is the so-called model-based processor which is based on a state-space representation of the normal-mode propagation model. If state-space solutions can be accomplished, then many of the current ocean acoustic processing problems can be analyzed and solved using this framework to analyze perfomance results based on firm statistical and system theoretic grounds. The model-based approach, is (simply) "incorporating mathematical models of both physical phenomenology and the measurement processes including noise into the processor to extract the desired information" (see (Candy,1986) for details). In this application, we seek techniques to incorporate the: (1) ocean acoustic propagation model; (2) sensor array measurement model; and (3) noise models (ambient, shipping, surface and measurement) into a processor to solve the associated localization/detection problems.

It has already been shown that this representation can be utilized for signal enhancement to spatially propagate both modal and range functions (Candy and Sullivan, 1992,1994). Specifically, using the normal mode model of the acoustic field, and a known source location, the modal functions and the pressure field were estimated from noisy array measurements in the following way. First, the propagation model is cast into state-space form. This model was then used to propagate both the modal (depth) and range functions, given the basic parameters (wavenumbers etc.) developed from the solution of the associated boundary value problem. There are basically two sets of equations in this representation: the state equation and the measurement equation. In our case, the state equation describes the evolution in space of the modal, whereas the measurement equation relates the states to the actual array measurements. In the stochastic case, an approximate Gauss-Markov model evolves allowing the inclusion of stochastic phenomena such as noise and modeling errors in a consistent manner. The Gauss-Markov representation includes the secord order statistics of the measurement noise and the modal noise. In our case, the measurement noise can represent the near-field acoustic noise field, flow noise on the hydrophones and electronic noise, whereas the modal/range noise can represent SVP errors, noise from distant shipping, errors in the boundary conditions, sea state effects and ocean inhomogeneities. Based on this framework, investigations were also made of model-based solutions to the signal enhancement, detection and related parameter estimation problems as well as a new technique for sound speed estimation (Candy and Sullivan,1993).

The next step is to develop a model-based processor to solve the localization problem depicted structurally in Figure 1 below. In terms of the current ocean acoustic signal processing approaches, we develop an alternative to matched-field processing that circumvents the boundary value problem solution and uses parameters extracted directly from ocean measurements to develop a model-based technique with identification in the same spirit as the solution presented for towed array processing (Candy and Sullivan,1989). We develop a model-based processor for a horizontally stratified ocean modeled by a normal-mode propagation that is capable of localizing an acoustic source in a hostile ocean environment. First, the theoretical issue of "identifiability" of the required parameters (wavenumbers, sound velocity profile, etc.) will be investigated employing the propagation model and measurement system (incorporating a typical sensor-array geometry). That is, the generic model-based processor structure in state-space form is given by: 


$$
\begin{gathered}
\hat{\phi}(z \mid z, \theta)=A(z, \theta) \hat{\phi}(z-1 \mid z-1, \theta)+K(z, \theta) \epsilon(z-1, \theta) \\
\hat{\theta}(z \mid z)=\hat{\theta}(z-1 \mid z-1)+K_{\theta}(z) \mathbf{e}(z-1)
\end{gathered}
$$

where $\phi$ is the modal function state vector, $A, K, K_{\theta}$ are the respective process and gain matrices, $\theta$ is the vector of unknown parameters including position (see Figure 1) and $\epsilon$ is the residual or so-called innovations sequence given by

$$
\epsilon(z-1, \theta)=\mathrm{p}(z-1)-C(z, \theta) \hat{\phi}(z \mid z-1, \theta)
$$

with $C$ the corresponding measurement matrix.

In order to analyze the performance of the processor, a simulator was developed to generate a known pressure field with noise at the array sensor locations. These noisy measurements were then be used to investigate the feasibility of the model-based processor to localize the source. Conceptually, the processor or banks of processors will attempt to find the "best" fit (in a minimum variance sense) of the model to the data and then use this model perform the localization using the residuals of the "best" fit to the data set.

\section{REFERENCES}

Baggeroer, A., W. Kuperman, and H. Schmidt. (1988). Matched-field processing: source localization in correlated noise as an optimum parameter estimation problem. J. Acoust. Soc. $A m, 83,(2), 571-587$.

Bucker, H.P. (1976). Use of calculated sound fields and matched-field detection to locate sound in shallow water. J. Acoust. Soc. Am., 59, 329-337.

Candy, J.V. (1990) Matched-field processing: a survey. LLNL Report, UCRL-JC-104587.

Candy, J.V. and E.J. Sullivan (1992) Ocean Acoustic Signal Processing: A Model-Based Approach J. Acoust. Soc. Am., 92, (6), 3185-320'.

Candy, J.V. and E.J. Sullivan (1993) Sound Velocity Profile Esimation: A System Theoretic Approach. IEEE Journal of Oceanic Engr., 18, 240-252.

Candy, J.V. and E.J. Sullivan (1994) Model-Based Processor Design for a Shallow Water Ocean Environment. To appear J. Acoust. Soc. Am.

Clay, C.S. and H. Medwin (1977). Acoustical Oceanography John Wiley \& Sons, New York.

Feuillade, C., D. Del Balzo, and M. Rowe (1989). Environmental mismatch in shallow-water matched-field processing: geoacoustic parameter variability. J. Acoust. Soc. Am., 85, (6), 2354-2364.

Hamson, R. and R. Heitmeyer. (1989). Environmental and system effects on source localization in shallow water by the matched-field processing of a vertical array. J. Acoust. Soc. Am., 86, 1950-1959. 
Hinich, M.J. (1973). Maximum likelihood signal processing for a vertical array. J. Acoust. Soc. Am., 54, 499-503.

Hinich, M.J. and E.J. Sullivan (1989). Maximum likelihood passive localization using mode filtering. J. Acoust. Soc. Am., 85, (1) 214-219.

Jazwinski, A. (1970). Stochastic Processes and FIltering Theory. Academic Press, New York.

Jensen, F.B and M.C. Ferla (1982). SNAP: The SACLANTCEN normal-mode acoustic propagation model. SACLENTCEN Report SM-121., SACLANT Undersea Research Centre, La Spezia, Italy.

Johnson, D.H., The application of spectral estimation methods to bearing estimation problems. Proc. IEEE, 70, 1018-1028.

Klemm, R. (1980). Use of generalized resolution methods to locate sources in random dispersive media. IEEE Proc., 127, Pt. F., 34-40.

Lager, D. L., Azevedo, S. G. and J.V. Candy. (1982). The application of large-scale state estimation to vibrating structures. 6th IFAC Symposium on Identification/System Parameter Estimation, Wash. D.C. or LLNL Report UCRL-86138.

Ljung, L. (1987). System Identification: Theory for the User Prentice-Hall, New Jersey.

Maybeck, J. (1979). Stochastic Models, Estimation and Control. Academic Press, New York, Vol. 1.

Mehra, R. (1970). On the identification of variances and adaptive Kalman filtering. IEEE Trans. Auto. Contr., 15, 175-184.

Mehra, R. and J. Peschon. (1971). An innovations approach to fault detection and diagnosis in dynamical systems. Automatica, 7, 637-640. Mendel, J. (1983), Optimal Seismic Deconvolution: An Estimation-Based Approach Academic Press, New York.

Moura, J.M. (1983). A spatial smoothing formulation for location systems. IEEE Trans. Ocean Engr., OE-8, 148-163.

Sage, A. and J. Melsa. (1971). Estimation theory with applications to communications and control. McGraw-Hill, New York.

Sullivan, E.J. (1987a). Passive localization using propagation models. SACLANTCEN Report, SR-117, SACLANT Undersea Research Centre, La Spezia, Italy.

Sullivan , E.J. and K. Rameau. (1987b). Pasive ranging as an inverse problem: a sensitivity study. SACLANTCEN Report, SR-118, SACLANT Undersea Research Centre, La Spezia, Italy.

Sullivan, E.J. and D. Middleton. (1993) Estimation and Detection Issues in Matched-Field Processing. IEEE Journal of Oceanic Engr., 18, 156-167.

Van Veen, B. and K. Buckley. (1988). Beamforming: a versatile approach to spatial filtering. IEEE ASSP Mag., 5(2), 4-24. 
Willsky, A.S. (1976). A survey of design methods for failure detection in dynamic systems. Automatica, 12, 601-611.

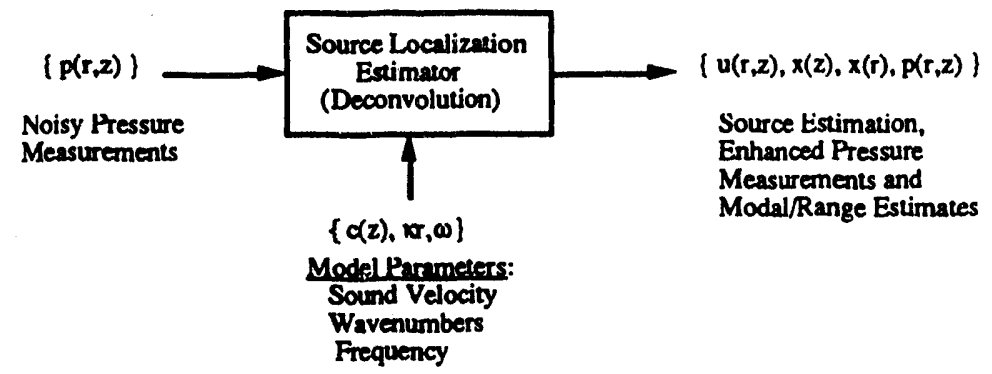

(a) Basic Problem No. 2

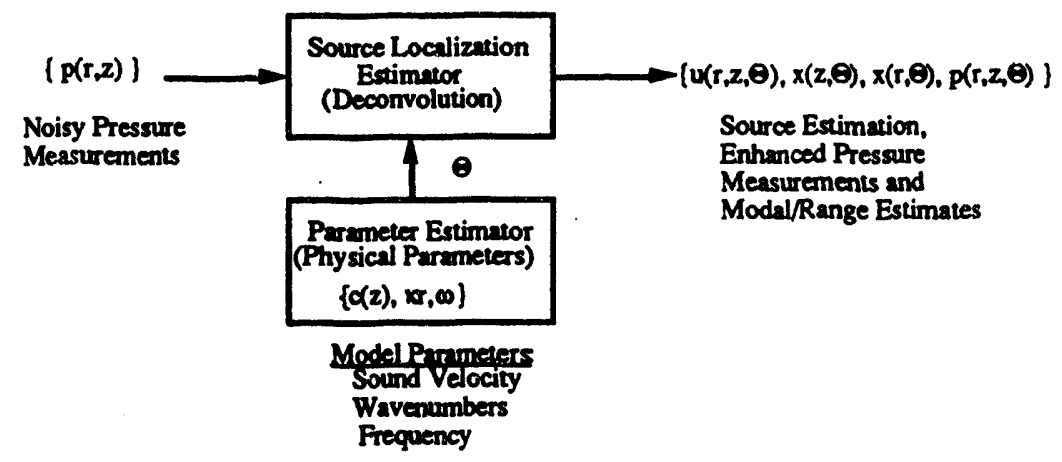

(b) Basic Problem No. 5

Figure 1. Model-Based Passive Localizer Structure: (a) Parameters known. (b) Parameters unknown. 

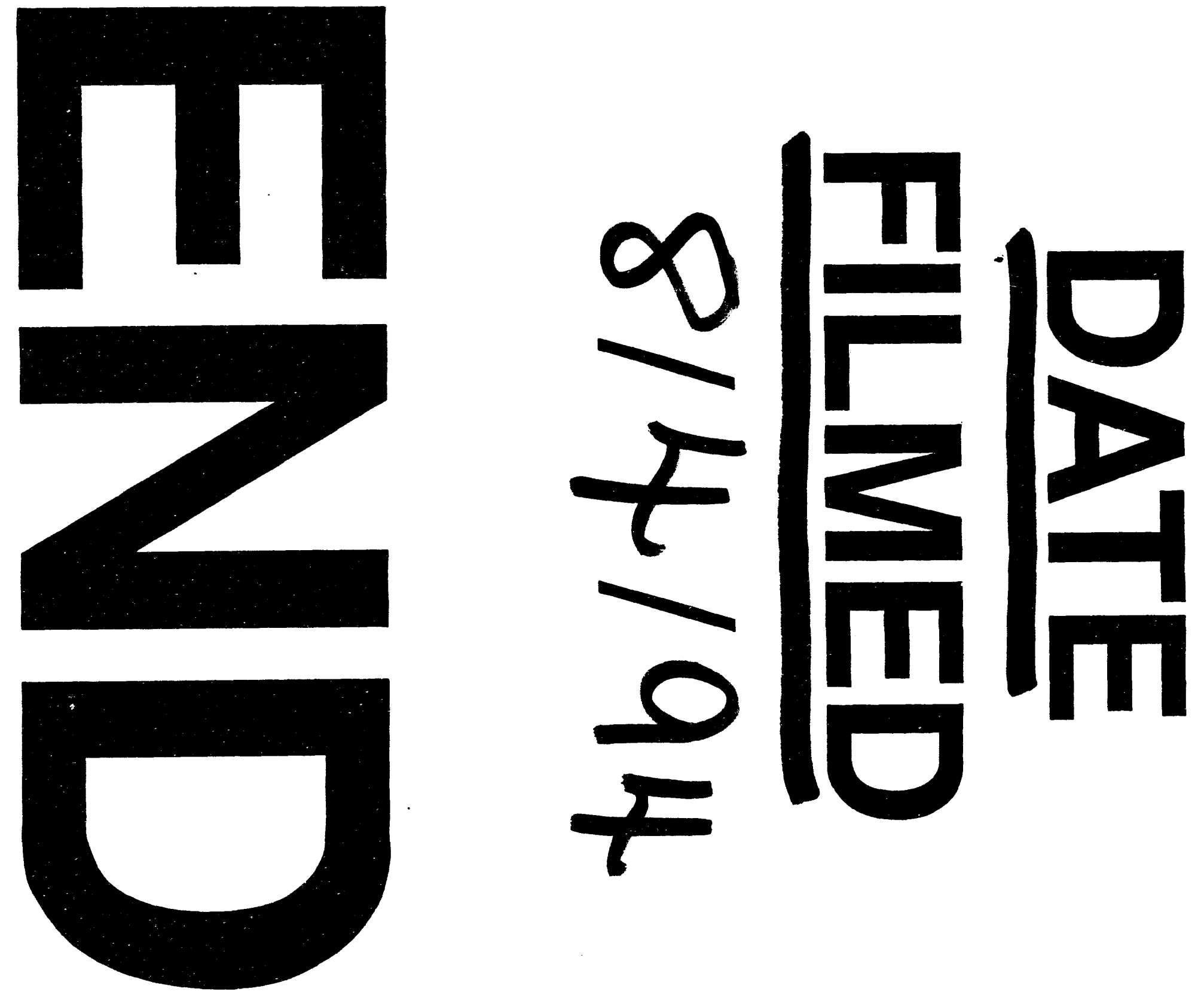


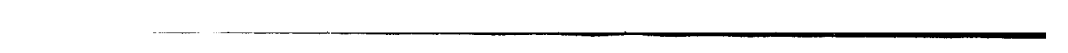

A 